\title{
Discipline-centred learning: an integrative model for medical undergraduate education
}

\author{
Dassanayake, T.L.
}

\section{Introduction}

Traditionally, education had been teacher centred. With the 1) availability of resources of knowledge other than the teacher, 2) industrialisation of education where student is the client; and 3) emergence of more individualised needs and preferences of the students in the industry, the term learnercentred education (also called student-centred learning) has gained popularity in many countries including Sri Lanka (Schweisfurth, 2011; Spencer \& Jordan, 1999). Among other limitations of implementing in the developing countries (Schweisfurth, 2011), studentcentred learning does not specify who pays for the education of the student, or to what profession the students are trained to when it applies to higher educational institutions.

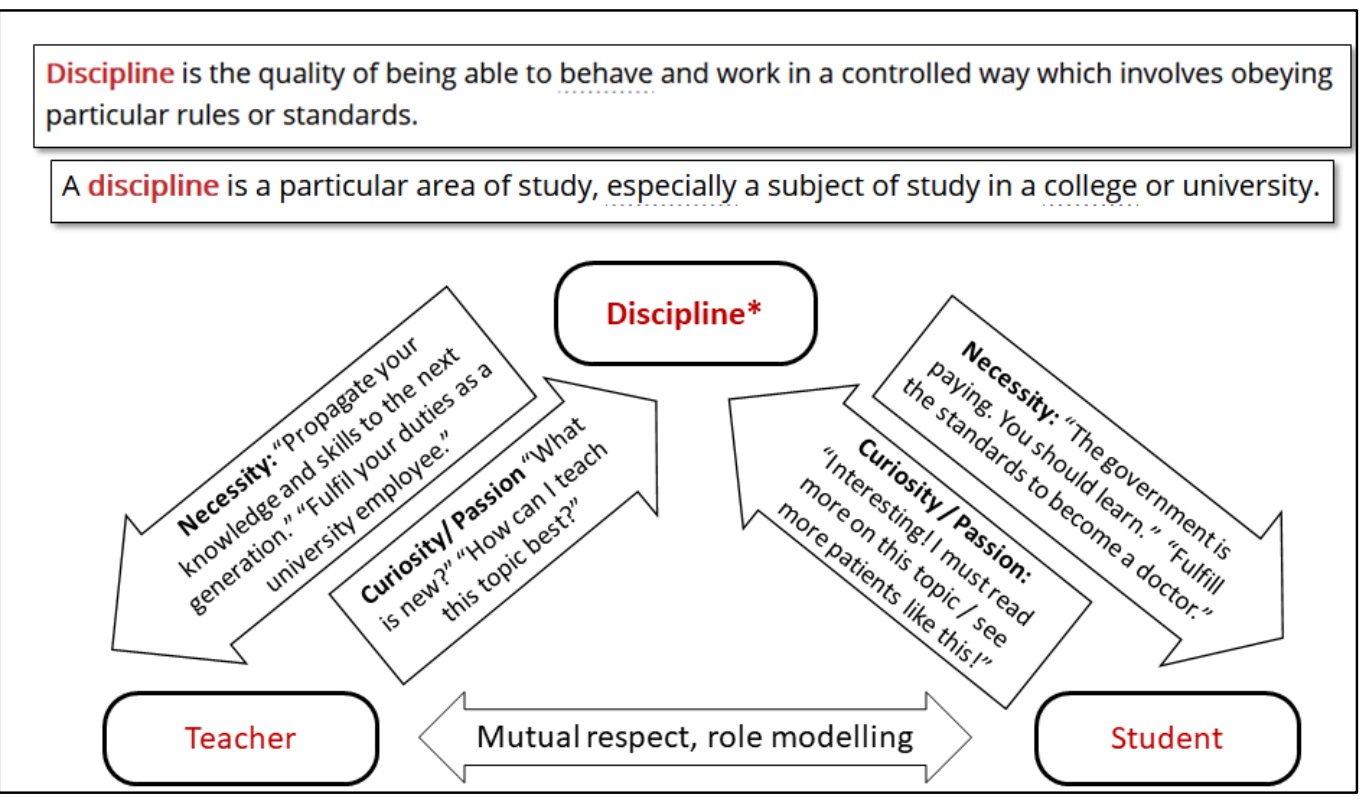

Figure 1: The discipline-centred model of undergraduate medical education.

Discipline-centred learning: model description

The scope of the present paper thus is to propose an integrative, discipline-centred model for undergraduate medical education in Sri Lanka (Figure 1).

Department of Physiology, Faculty of Medicine, University of Peradeniya, Peradeniya 20400, Sri Lanka.

Corresponding author: Prof Tharaka Lagath Dassanayake tharakad@pdn.ac.lk
First, the medical students themselves do not pay for their education and are trained for a licensing examination, and thus (rightfully) do not have the full liberty to pace, defer or choose the content of learning highlighted in studentcentred models (McMahon, 2005; Schweisfurth, 2011). Second, once graduated and licensed to practice, their work is not primarily doctor-centred, but job-centred i.e., the duty-of-care governed by the rules, regulations of the health care system, and medical ethics in general. 
Third, the teachers are also bound by rules, regulations and work ethics of the universities and Teaching Hospitals that employ them. The model also takes into account the passion both the teacher and the student direct towards the medical discipline, as the 'disciples' living at two different stages of the same career.

The discipline-centred model triangulates the discipline, the teacher, and the student (Figure 1). The discipline which is at the apex of the model represents two definitions of the English word. The first refers to the quality of being able to behave and work in a controlled way which involves obeying particular rules and standards. This imposes certain necessities upon the teachers and the students in a topdown fashion (Figure 1, top-down arrows from apex): 'Necessity is the mother of invention'. To this end the teachers (the university academic staff members) are expected to fulfill duties assigned to them by the university, as employees. At a different level the medical teachers are also obliged to propagate their knowledge and skills to the next generation of their profession. Within the institution, these obligations are conveyed to the teacher in many forms, including the Universities Act, their appointment letter, duty assignment letters, staff development programmes and curriculum documents etc. The necessities imposed on the medical students is primarily governed by the fact that the government is paying for their education to become licensed practitioners. This is operationalised in the form of course requirements, examination rules and regulations etc. culminating in the final licensing examination. Delineating and documenting such necessities in detail; and making them available to students before the actual event is essential. In many countries, this comes as a contract document between the institution and the enrolee, and/or a student handbook / information pack.

The second meaning of the concept discipline in the model refers to the particular area of study taught at the university (e.g., physiology, surgery etc.). It is fair to assume that both the teacher and the student have chosen to be at the university because they show a passion and curiosity to the discipline at hand (e.g., human physiology in the first year): 'If necessity is the mother of invention, curiosity is the father!' This passion /curiosity is represented by the bottomup arrows directed towards the apex from each other corner at the base of the triangle in Figure: 1. Passionate university teachers seek new knowledge (through continuing professional development and through their own research), and continuously fine-tune the methods they deliver the knowledge and skills to their students. Perhaps the teachers most remembered are the ones who deliver the content with great spontaneity! The students gather knowledge and skills directly from their teachers or external resources. The passion/curiosity of the students in medical training is marked by the tendency of the students to seek more knowledge and skills based on what they acquire-a snowball effect already well described in student-centred learning models (McMahon, 2005; Spencer \& Jordan, 1999).

The discipline-centred model so far explained how the teachers and the students interact in the academic environment with the discipline/s. What governs the direct interaction between the teachers and the student body? Transferring egalitarian values of the contemporary society to adult education, mutual respect and role modelling lays the foundation to direct teacherstudent interactions (bidirectional arrow at the base of the triangle in Figure 1). Both parties should at least obey the top-down necessities for this mutual respect to be established. Neither a student who frequently cuts classes at the expense of the government money nor a teacher who is habitually late for lectures would garner the respect of the other. Role modelling is a ubiquitous form of learning. It is pertinent to the teacher-student interactions in medicine that evolved as an apprenticeship-based discipline. Role modelling can propagate both good and bad practices (and attitudes) in medical training (Benbassat, 2014). In the discipline-centred model, the bad habits of both parties are kept under check by top-down conditions laid out by the discipline, preventing obnoxious teachers breeding obnoxious apprentices. In this information age where certain secular trends outpace the age-related acquisition of skills, some undergraduates 
show better English language and digital media skills than the teachers, and thus could in fact be role models to their teachers in some ways, and the teacher should be open to learn from such experiences (hence the bidirectional arrow at the base).

\section{Conclusions}

In summary, conceptualizing the modern medical education industry (whether it is government or privately funded) as a direct, stand-alone transaction between a teacher and a student has its limitations (Schweisfurth, 2011). Critically, both teacher- and studentcentred learning models gives a secondary importance to the specific discipline that is learned, and do not specify who funds the learning process. The discipline-centred learning acknowledges the three-way interaction among the discipline, the teacher, and the student. More specifically, the model:

- integrates the principles of adult learning with

- the cognitive dispositions and interactions of the teachers and students,

- within the legislative and administrative and financial framework of the state-run university system of Sri Lanka

- While leaving room for subject-specific improvisations.
Finally, the discipline-centred model is not proposed as a metaphorical touchstone that validates or accredits medical teaching programmes. Rather the model is expected to serve as an intellectual foundation upon which 1) the medical academia may orient their undergraduate programmes, and 2) medical undergraduates can orient themselves in the arena of institutionalised, professional, adult education.

Acknowledgements: The author thanks Dr. Dewasmika Ariyasinghe for providing valuable comments on the draft manuscript.

\section{References}

Benbassat, J. (2014). Role modeling in medical education: the importance of a reflective imitation. Academic Medicine: Journal of the Association of American Medical Colleges, 89(4), pp. 550-554.

McMahon, T.P. (2005). Student-centred learning: what does it mean for students and lecturers?, from https://www.ucd.ie/t4cms/Student\%20 Centered\%20Learning\%20Article.pdf.

Schweisfurth, M. (2011). Learner-centred education in developing country contexts: From solution to problem? International Journal of Educational Development, 31(5), pp. 425-432.

Spencer, J.A., \& Jordan, R.K. (1999). Learner centred approaches in medical education. BMJ, 318(7193), pp. 1280-1283. 